\title{
Drug interaction analysis-Nigella sativa L.seed (Black Cumin) ethanolic extract on anti-seizure activity of Phenobarbitone sodium
}

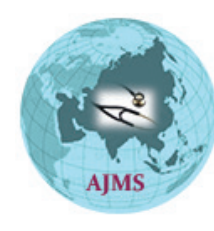

\author{
Lovelyn Joseph ${ }^{1}$, Rejeesh Edavan Puthallath², Sudarshanram Narayan Rao ${ }^{3}$ \\ ${ }^{1}$ Associate Professor, Department of Pharmacology, PK Das Medical College, Vaniyamkulam, Kerala, India \\ ${ }^{2}$ Associate Professor, Department of Pharmacology, MountZion Medical College, Adoor, Kerala, India \\ ${ }^{3}$ Senior Professor, Pharmacology (Rtd), Independent Researcher
}

Background: Multidisciplinary therapy is gaining popularity and drug herb interactions is one of the biggest risk factor contributing to therapeutic failures or toxicities. Apart from analysis of one of such Drug-Herb combinations, this work also aims at emphasizing need for ethnopharmacovigilance practices. Aims and Objectives: Herb-Drug Interaction analysis between Nigella sativa seed ethanolic extract and Phenobarbitone sodium in maximal electroshock seizure in Swiss albino mice with a modified isobolographic analysis. Materials and Methods: Experiment model was Maximal electroshock seizure in Swiss albino mice. Dose ratios of the combination tested were NsEE: Phenobarbitone; 3:1 (NsEE75\%: Pbt25\%), 1:1, 1:3. Analysis was done with modified isobolographic analysis. Results: Nigella sativa seed ethanolic extract exhibit synergistic interaction with Phenobarbitone sodium at $1: 1$ and $1: 3$ dose ratios and antagonistic interaction at 3:1 combination. The parameter measured was Hind limb tonic extensor phase in maximal electroshock seizure test in Swiss albino mice.Conclusion: The study showed that interaction profile of Nigella sativa extractphenobarbitone combination is dose dependent and requires well designed posological studies in epileptic patients to formulate dose adjustment guidelines for multidisciplinary therapy with the herb and Phenobarbitone, also to avoid food drug interactions.

Access this article online

Website:

http://nepjol.info/index.php/AJMS DOI: 10.3126/ajms.v11i2.27308 E-ISSN: 2091-0576 P-ISSN: $2467-9100$

Key words: Nigella Sativa; Maximal electroshock seizures; Epilepsy; Phenobarbitone;

Ethnopharmacovigilance

\section{INTRODUCTION}

Majority of epileptic patients from developing world depend on herbal medicines. Insufficient supply of drugs, unavoidable adverse effects and incomplete seizure control are major issues. Standardization of herbal medicines as per pharmacological principles and therefore analysis of drug interactions is the resolution for the scenario.

This research work is part of such an effort to validate and standardize antiepileptic application of black cumin (Nigella sativa seed), which has been part of agriculture since ages, both for their culinary uses and therapeutic values. ${ }^{1}$ These herbs exhibited potent antiseizure property in mice models which are published earlier. ${ }^{2}$ In current study of drug interaction between Phenobarbitone sodium with Nigella sativa seed ethanolic extract in Maximal electroshock induced seizures was studied with a modified isobolographic analysis.

\section{MATERIALS AND METHODS}

\section{Plant materials}

The seeds of Nigella sativa (English: Small Fennel, Black Cumin) were procured locally from Mangalore. Identified and confirmed the botanical name of the plant as Nigella sativa by Taxonomist, Department of Applied Botany, Mangalore University, Karnataka. 


\section{Extraction}

Nigella sativa shade dried seeds were powdered and extracted with Soxhlet apparatus, in portions of $200 \mathrm{~g}$, with $99 \%$ ethanol at $60^{\circ} \mathrm{C}$ temperature for 3 days. After exhaustive extraction, the collected ethanolic extract (NsEE) was dried in a water bath at $50^{\circ} \mathrm{C}$ and stored under refrigeration. The final yield of the extraction was $25 \% .^{2}$

\section{Experimental animals}

The experimental protocol was approved by the Institutional Animal Ethics Committee (IAEC), Yenepoya University and care of laboratory animals was taken as per CPCSEA guidelines. Animals were housed (Animal house, Yenepoya University, Reg.no 347/CPCSEA) in polypropylene cages and maintained at temperature $\left(25 \pm 2^{\circ} \mathrm{C}\right)$ and light (light period, 06.00- 18.00) in a controlled room with relative humidity of $50-55 \%$. Food and water were provided ad libitum. Experiments were carried out between 15:00 and 19:00 h. ${ }^{3}$

\section{Experimental procedures}

Screening Anticonvulsant Activity-Maximal electroshock seizure test: Maximal electroshock seizures test was performed in mice with 0.2 -second series alternating current with $50 \mathrm{~Hz}$ frequency and an intensity of $60 \mathrm{~mA}$, applied through ear electrode primed with an electrolyte solution. Reduction in duration of tonic hind limb extension was taken as a measure of efficacy in this test. ${ }^{4,5}$

\section{Interaction with standard drugs}

Thirty minutes after intraperitoneal administration of the drugs, animals were exposed to maximal electroshock seizure.

Inclusion criteria for animals

Male Swiss albino mice 25-30g, 3-4 months old in good health.

ROA - intraperitoneal (i.p)

Method of analysis of drug interactions $s^{6,7,8,9}$

A. Tabulated Duration of HLTE(Hind Limb Tonic Extensor Phase of maximal electroshock seizure in mice) of various experimental groups (HLTEExp), Statistical analysis was done with ANOVA followed with Dunnett's multiple comparison tests.

\begin{tabular}{lcc}
\multicolumn{3}{l}{ Table 1: Grouping and dose selection } \\
\hline Grouping (n=6) & NsEE & $\begin{array}{c}\text { Phenobarbitone } \\
\text { sodium }\end{array}$ \\
\hline Group 1 - NsEE 100\% & $900 \mathrm{mg} / \mathrm{kg}$ & 0 \\
Group 2 - NsEE: PBT; 75:25 & $675 \mathrm{mg} / \mathrm{kg}$ & $2.5 \mathrm{mg} / \mathrm{kg}$ \\
Group 3 - NsEE: PBT; 50:50 & $450 \mathrm{mg} / \mathrm{kg}$ & $5 \mathrm{mg} / \mathrm{kg}$ \\
Group 4 - NsEE: PBT; 25:75 NsEE & $225 \mathrm{mg} / \mathrm{kg}$ & $7.5 \mathrm{mg} / \mathrm{kg}$ \\
Group 5- PBT 100\% & 0 & $10 \mathrm{mg} / \mathrm{kg}$ \\
\hline
\end{tabular}

B. Simulated the additive HLTE (HLTEAdd) duration for 75:25, 50:50, 25:75 combinations from the HLTE values of $100 \% \mathrm{NsEE}$ and $100 \%$ Standard drug using the formula,

[(mean duration of HLTE NsEE 100\%* N\%) + (mean duration of HLTE PBT 100\%*P\%)]

$\mathrm{N} \%=$ Fraction of $\mathrm{NsEE}$

$\mathrm{P} \%=$ Fraction of PBT

C. Dose response curve of the duration of the tonic hind limb extensor phase HLTEExp and HLTEAdd ( $Y$ axis) was plotted against different dose percentage of standard drug (X axis).

D. If HLTEExp fall below the HLTEAdd curve the combination is synergistic. If HLTEExp fall on HLTEAdd Curve the combination is additive. If HLTEExp fall above HLTEAdd the combination is antagonistic.

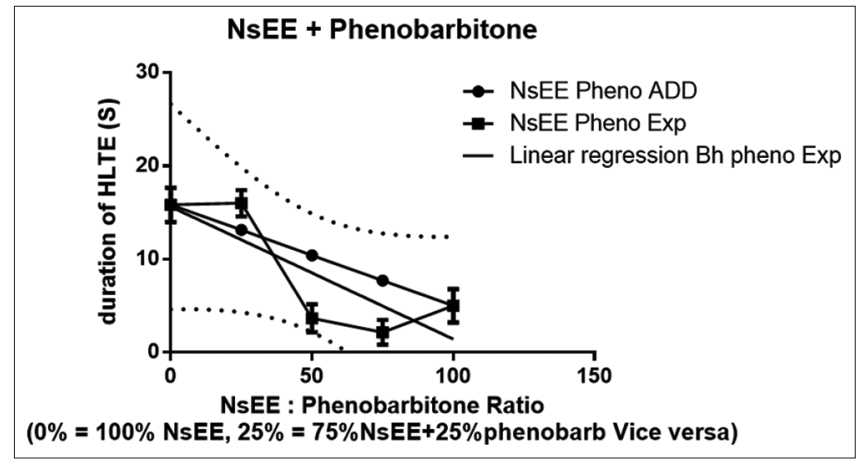

Figure 1: Dose response curve of the duration of the tonic hind limb extensor phase HLTE Exp and HLTE Add (Y axis) was plotted against different dose percentage of standard drug ( $X$ axis).

\begin{tabular}{|c|c|c|}
\hline Group & $\begin{array}{c}\text { Mean HLTE } \\
\text { (seconds) }\end{array}$ & $S D$ \\
\hline Group 1 - NsEE100\% & 15.8 & 1.8 \\
\hline Group 2 - NsEE: PBT; 75:25 & 16 & 1.4 \\
\hline Group 3 - NsEE: PBT; 50:50 & 3.7 & 1.5 \\
\hline Group 4 - NsEE: PBT; 25:75 NsEE & 2.2 & 1.3 \\
\hline Group 5 - PBT $100 \%$ & 5 & 1.8 \\
\hline
\end{tabular}

Table 3: Simulated the additive HLTE (HLTE Add) duration for $75: 25,50: 50,25: 75$ combinations from the HLTE values of $100 \%$ NsEE and $100 \%$ standard drug using formula

\begin{tabular}{lc}
\hline Dose Ratio & HLTE Add (seconds) \\
\hline NsEE: PBT; 75:25 & 13.12 \\
NsEE: PBT; 50:50 & 10.41 \\
NsEE: PBT; 25:75 & 7.7 \\
\hline
\end{tabular}




\section{RESULTS}

Inference: NsEE: Phenobarbitone combination exhibited Synergism at 1:1 and 3:1 since HLTEExp fell on HLTEAdd Curve. At 3:1 dose ratioHLTEExp fell above HLTEAdd and the combination is antagonistic (Figure 1).

\section{DISCUSSION}

Herb-Drug Interaction profile of Nigella sativa ethanolic extract on antiseizure activity of Phenobarbitone in mice maximal electroshock model is significant and dose dependent as seen with the results and analysis using modified isobolographic method. Wide spread use of the herb for culinary and medicinal purposes increases the risk of accidental drug interactions, as in most cases the doctor are not informed about the use of the herb as both the patient and doctor may not know the potential for such herb drug or food drug interaction between black cumin(Nigella sativa seeds) and Phenobarbitone.

Avoiding concomitant use of the herb during treatment with phenobarbitone is advisable to avoid undesirable drug interactions; until we elucidate dose response relationship of the combination in patients and prepare a dose adjustment table for the herb and Phenobarbitone.

The interaction profiling of the combination at various dose ratios in epileptic patients is essential for the application of a multidisciplinary therapy, especially to address treatment gap due to insufficient supply and cost of the drugs.

Phenobarbitone like most of the antiepileptic agents pose high risk of drug interactions and a narrow safety margin, requiring target level (plasma therapeutic concentration) guided dosing strategy aided with therapeutic drug monitoring (TDM). Most of the parts of the world TDM facilities are not available or are not affordable leading to unnecessary incidents of therapeutic failures and toxic effects.
These findings and reports from isobolographic analysis indicate detailed, well designed clinical studies with the herb and tailor the doses of the combination. Until then the combined use of Nigella sativa products with Phenobarbitone sodium in seizure patients should be considered contraindicated.

\section{REFERENCES}

1. Sharma N, Ahirwar D, Jhade D and Gupta S. Medicinal and Pphamacological potential of Nigella sativa: A review. Ethnobotanical Leaflets 2009; (7): 11.

2. Corneanu G, Corneanu M, Crăciun $\mathrm{C}$, Ciupină V, Zagnat $\mathrm{M}$ and Atyim P. Bioactive Substances from the Nigella sativa Seeds. Academy Of Romanian Scientists 2012; 1(1): 13-28.

3. Rejeesh, EP, Lovelyn $\mathrm{J}$ and Rao SN. Anticonvulsant activity of Nigella Sativa ethanolic extract in Maximal Electroshock Seizure model.International Journal of Universal Pharmacy and Bio Sciences 2013; 2(5):36-44.

4. James P. Stables and Harvey J. Kupferberg.CPCSEA guidelines for laboratory animal facility, Page No: 914. Cpcsea.nic.in. (2020). Home: Committee for the Purpose of Control and Supervision of Experiments on Animals. [online] Available at: http://cpcsea.nic.in/ [Accessed 1 Jan. 2020].

5. Loscher $W$ and Schmidt $D$. Which animal models should be used in the search for new antiepileptic drugs? A proposal based on experimental and clinical considerations. Epilepsy Res. 1988;2:145-181.

6. Lovelyn Joseph, Rejeesh EP and Rao Sudarshanram Narayan Supraadditive Effect of Hydroethanolic Extract of ValerianaWallichii (Indian Valerian) Root and Phenobarbitone Against Maximal Electroshock Seizure In Mice. International Journal of Bioassays. 2013; 2(8), 1158-1161.

7. Litchfield $\mathrm{J}$ and Wilcoxon F. A simplified method of evaluating dose-effect experiments. Journal of Pharmacology and Experimental Therapeutics 1949; 96 (2): 99-113.

8. Luszczki J, Borowicz K, Swiader M and Czuczwar S. Interactions between oxcarbazepine and conventional antiepileptic drugs in the Maximal Electroshock induced Seizure test in mice: an isobolographic analysis. Epilepsia2003; 44 (4): 489-499.

9. Luszczki JJ and Czuczwar SJ. Preclinical profile of interactions between loreclezole and conventional antiepileptics against maximal electro convulsions in mice: an isobolographic analysis. [abstract] $8^{\text {th }}$ Congress of the European Federation of Neurological Societies, Paris, France. Eur J Neurol 2004; 11(Suppl 2): 227.

\footnotetext{
Authors Contribution:

RJ - Concept and design of the study, reviewed the literature, conducted experiment, data collection and analysis, manuscript preparation and critical revision of the manuscript; LJ - reviewed the literature, manuscript preparation and critical revision of the manuscript; SNR- Critical revision of the manuscript.

Work attributed to:

Analyze Drug-Herb Interaction analysis and also to emphasize need for mandating Ethnopharmacovigilance practices.

Orcid ID:

Dr. Rejeesh Edavan Puthallath - (1) https://orcid.org/0000-0001-9927-9221

Dr. Lovelyn Joseph - (i) https://orcid.org/0000-0003-2148-4107

Source of Support: Source(s) of support in the form of grants equipment, drugs, or all of these- Ethnopharmacology Unit, Department of Pharmacology, Yenepoya University, Conflict of Interest: None declared.
} 